\title{
Whose Future is it Anyway?
}

\section{Christopher Coenen}

Published online: 1 August 2017

C) Springer Science+Business Media B.V. 2017

The April issue of our journal featured a special section on both the conceptual and the empirical aspects of the development and application of future visions in science and technology discourse. Various contributions to this special section and, indeed, the entire section took the concept of "visioneering" as it was developed by the historian Patrick McCray, most prominently in his 2013 book The Visioneers: How a Group of Elite Scientists Pursued Space Colonies, Nanotechnologies, and a Limitless Future [1], as a starting point for their own analyses and reflections.

I am therefore exceptionally grateful that Patrick McCray has agreed to respond to this special section and the articles it included in our present issue, using this opportunity to reflect on his own concept and its genesis. The development of his concept goes back to the middle of the last decade, the period when this journal was founded by John Weckert. Early socialscientific and humanist discourse on nanoscience and nanotechnology was already highly interdisciplinary and had to deal with strongly futurist visions to a greater extent than today [2]. As a historian, McCray was particularly interested in the history of how nanotechnology was imagined. He therefore pioneered the analysis of the futurist discussions about technoscience and the future that had been

C. Coenen $(\bowtie)$

Institute for Technology Assessment and Systems Analysis, (ITAS), Karlsruhe Institute of Technology (KIT), POB 3640, 76021 Karlsruhe, Germany

e-mail: christopher.coenen@kit.edu taking place since the 1980 s, in which nanofuturism played a crucial role. In his thoughtful, inspiring essay for the present issue, McCray offers fascinating insights into how his research interests and approach developed in this context and explains his view of the future as a "sharply contested terrain", which different groups try to control by a wide variety of means. Focusing on emerging and visionary technologies with their "protean capacity" to utterly transform our societies and, indeed, the human condition, he contributed decisively to the unearthing of a hitherto largely hidden pre- and early history of nanotechnology. As McCray points out in his essay, taking Elon Musk as an example, the influence of visioneers is still strong today. I would argue it is even stronger today than it was in the 2000 s, since some key players in the central industries of our digital age are now among the most vocal technofuturists; and, in line with McCray's notion of a visioneer, the leading visioneers of our day are more often engineers than was the case about ten years ago. As the ideology subscribed to by these visioneers, transhumanism is becoming ever more firmly rooted in the public discourse constructed by engineers, industrialists, and technology-savvy natural scientists, displacing the more academic influence of philosophers and social scientists with transhumanist beliefs. The subsequent surge in public interest has entailed a considerable amount of mass-media reporting, which has in turn attracted a certain degree of interest in this topic from policy makers and led to a number of book-length critiques of what is seen by 
some as the transhumanist agenda of major players in the IT industry.

While I cannot do justice to all the ideas and observations in McCray's essay, which will undoubtedly do much to help advance the study of technoscientific futures, I wish to draw your attention specifically to his reflections on the "Californian ideology" and the myth of Silicon Valley. He points out that there are many Silicon Valleys, which include all the working class people (factory workers, gardeners, nannies, and so on) who make "the lives of the tech gurus possible", and he reminds us that such techno-libertarians as the notorious Peter Thiel have apparently forgotten the debt Silicon Valley owes to the entrepreneurial state and to publicly funded education, research, infrastructure and technology development. I strongly sympathise with McCray's plea for us to look more closely at the motivations and political leanings of technological disruptors, and their tendency to believe that technological change can stand in as a substitute for political action and social reform. As he convincingly argues, future research into visioneering along the lines of the articles in the special section of our journal's April issue could be conceived in ways that ensure more voices and views are included from the outset, taking account of the power structures at play in previous visioneering processes. As I argued in my editorial for the April issue, it has become obvious that the creation and use of radical, far-reaching visions of the future in discourse on research and technology development are themselves activities that require reflection on responsibility in research, innovation, and science policies and necessitate historically informed, culturally diverse, more participatory deliberation about visions of the future.

While the book review by Devan Stahl in the present issue discusses an important volume on transhumanism in which this ideology of current and historical visioneers is analysed from a wide variety of perspectives, two of the articles in the present issue have the potential to be recognised as major contributions to this field of research and discussion in their own right. In their article, Hub Zwart and colleagues argue that, in order to restore the emancipatory force of knowledge in a Habermasian sense, critical reflection now needs to take place in new settings for the exchange of ideas and mutual learning, in organised processes of deliberative and distributed reflection. After providing insights into the results of a major public and stakeholder dialogue project on neuro-enhancement that was funded by the
European Union, they make a case for citizens to be actively involved in imaginative, social laboratory-type settings, which would be designed to critically scrutinise future scenarios and help ordinary people become coauthors rather than targets of technological change. The analyses in Andy Miah's article explore the intersections of two urgent, much-discussed current issues in science and technology studies, namely the use of social media for science communication and the new ideal of citizen science. He argues for a notion of citizen science that is not only about laypeople engaging with and supporting science, but extends to a more encompassing notion of the democratisation of science "as a project that is coproduced, collectively owned, and crucially meaningful to people's lives". His article shows how important it is to embed reflections on science and technology in broader contexts such as the discussions about the political upheavals of our times. Moreover, Miah makes the strongest case for speculative ethics I have read so far - thereby contributing to a discussion that was inaugurated in our journal in its very first issue [3] -, and combines this with a plea for a democratisation of the social shaping of science and technology based on scientific agency.

Although I have argued elsewhere [4] that the strategic use of unrealistic visions, in which the boundaries separating these visions from salvation ideologies and mythical thought are blurred, can be detrimental to both science and public discourse on science, I fully agree with Miah that science fiction - and other fiction genres as well - constitute an important resource for public engagement with technoscience, and the ethics of new and emerging technologies in particular. At the same time I agree with Erik Thorstensen when he argues - in his article on the use of Golem stories in discussions of the ethical aspects of new and emerging technologies that it is very difficult to universalise "specific moralities from singular myths or stories". His analysis also demonstrates that the uses of historical fiction in discourse on new and emerging technologies are as complex as the uses to which future visions are put in this context.

Arguing that it is difficult, even for those who have been active participants or observers in the debates on nanotechnology and related initiatives, to see where progress has been made, and is still needed, in terms of responsible innovation in nanotechnology, Diana Bowman analyses regulatory and political activities that have been concerned with nanotechnology since the mid-2000s. She takes an influential report co- 
published by the Royal Society and the Royal Academy of Engineering in the UK in 2004 as the starting point for her analysis, focusing on its eight recommendations that specifically dealt with regulation and governance. Touching on developments at the EU level as well as in the UK and a number of other states, Bowman provides insights into a wide range of regulatory aspects of nanoscience and nanotechnologies.

Last but not least, the present issue features an article by Jennifer Cheung and Gregor Wolbring on the points of view expressed by organ procurement organisation staff concerning new, emerging, and future technologies. These "frontline workers" deal with organ donors and the public, for example facilitating the process of deceased organ donation by approaching a potential donor's relatives or other loved ones, and by providing in-service presentations to health professionals. Such foot soldiers of medical and technoscientific progress, as they could be called, are often forgotten in academic or organised public discourse on new and emerging technologies. The authors make a case for involving this group of professionals more often in governance discussions about technological futures, and the same case could be made for similar professional groups as well.

In an earlier editorial [5], I argued that discourse on responsible research and innovation (RRI) needs to be more socially specific and inclusive if it is to foster a better understanding of the challenges and opportunities thrown up by RRI at a time of widespread social and cultural crisis. Since then, this impression of mine has been further reinforced. Following Wolbring and others, I would argue that governance discourse on new, emerging, and future technologies should be much more - and much more specifically - inclusive. With Miah and others, I believe that social media on the one hand and the interfaces between art and science on the other can be important, post-hierarchical instruments with which to co-construe futures. Like McCray and others, I feel it is vital to look more closely at the broader socioeconomic settings in which the new cult of the engineer-genius is flourishing (and has almost completely replaced the older cult of the artist-genius). And I fully agree with Erik Fisher when he writes that, "our intellectual and practitioner community should examine and enhance its capacities to anticipate, engage, and perhaps help lay the groundwork for newly reconfigured socio-technical arrangements" at a time of "cultural and political upheavals" ( [6], 1). Fisher argues that three features of RRI may enable us to respond more effectively to the present popular discontent and, ideally, help channel it towards notions of collective responsibility and stewardship: its broadly social, nonelitist approach, its openness to grass-roots initiatives, and its ethos of care and creativity. He also provides a number of recent examples that may be deemed instances of a growing recognition, even among representatives of the Silicon Valley culture criticised by McCray, that innovation needs to be more socially responsible. I could not agree more.

From creative freelancers and researchers who often live in precarious economic situations to those working and middle class people who will lose, or already have lost, their jobs as a result of increasing automation, disruptive technoscientific progress has many victims, even in the most technologically developed countries. If technoscientific progress continues to fundamentally challenge our social order and disrupt the fabric of our societies, those who study new and emerging technologies and often facilitate public discussions about them will have to make sure the points of view and interests of all parts of society are taken into account, something that will also be of benefit to them as citizens of our threatened democratic polities. They could, for example, organise or support citizen conferences, hacker spaces, or stakeholder workshops in those parts of our countries that are already being devastated by the impacts of socially irresponsible technological progress. And it is their task to ask and publicly discuss the hard questions: How can our societies be re-organised in the light of the rapid progress that is taking place in many technological fields? What are we all going to do once we reach the point where, at least in Europe and North America, the Western utopia (of humankind being freed from toil and all kinds of unpleasant labour) becomes a reality? If we want the future to be ours in the broadest sense, we would be well advised to help develop more inclusive approaches to the creation of sociotechnical visions of the future, and to find new ways of fostering collective responsibility in technology development and diffusion.

\section{References}

1. McCray P (2013) The visioneers: how a group of elite scientists pursued space colonies, nanotechnologies, and a limitless future. Princeton University Press, Princeton

2. Coenen C (2017) Visions making sense of the present and cocreating the future. NanoEthics 11(1):1-2 
3. Nordmann A (2007) If and then: a critique of speculative nanoethics. NanoEthics 1(1):31-46

4. Coenen C (2015) The earth as our footstool - visions of human enhancement in 19th and 20th century Britain. In: Bateman S, Gayon J, Allouche S, Goffette J, Marzano M (eds) Inquiring into human enhancement: interdisciplinary and international perspectives. Palgrave Macmillan, Basingstoke, pp 183-204

5. Coenen C (2016) Broadening discourse on responsible research and innovation (RRI). NanoEthics 10(1):1-4

6. Fisher E (2017) Responsible innovation in a post-truth moment. Journal of Responsible Innovation 4(1):1-4 